\title{
Compositional Semantics of German Prefix Verbs
}

\author{
Maria Wolters \\ Institut für Kommunikationsforschung und Phonetik \\ University of Bonn \\ Poppelsdorfer Allee 47, D-j3115 Bonn \\ mwo@asl1. ikp.uni-bonn.de
}

\begin{abstract}
A compositional account of the semantics of German prefix verbs in HPSG is outlined. We consider only those verbs that are formed by productive synchronic rules. Rules are fully productive if they apply to all base verbs which satisfy a common description. Prefixes can be polysemous and have separate, highly underspecified lexical entries. Adequate bases are determined via selection restrictions.
\end{abstract}

\section{The Problem}

Determining the semantics of unknown words which can be derived from lexicon entries is highly desirable for natural language understanding (Light, 1996). In this paper, I sketch a compositional account of the semantics of German prefix verbs derived from a verbal base, concentrating on those verbs that can be generated by a productive word formation rule. Like (Witte, 1997), I assume that the meaning of most of these verbs can be derived compositionally by unifying the semantic representations of its constituents. Example:

$$
\begin{aligned}
& \text { durch + laufen ('through + to run') } \Rightarrow \\
& \text { durchlaufen ('to run through') }
\end{aligned}
$$

This is an instance of a common rule which can be summarized informally as

$$
\begin{aligned}
& \text { 'durch' + VERB }[+ \text { motion, +agentive }] \Rightarrow \\
& \text { VERB through a space }
\end{aligned}
$$

When a prefix verb is lexicalized, its meaning frequently shifts due to language change and metaphorical usage (Mayo et al., 1995). For example, 'durchlaufen' is mostly associated with the meaning "passing through ail stages of a process":

Er durchläuft die Schulung. He passes through the training.

\section{The Semantics of Prefix Verbs}

Frequently, the prefix modifies features of the base verb such as valency or aspect ${ }^{1}$. For example, while 'eilen' ('to haste') is an activity, 'etw. durcheilen' ('to haste through sth.') is an accomplishment. I assume that the prefix entry provides a highly underspecified blueprint of the structure of the prefix verb; therefore, I regard the prefix as the head of the prefix verb (but see (Bauer, 1990)).

The values for all features of the prefix verb are obtained from the base verb via structure sharing, except for basic morphological information and the information to be modified. In other words, the values of all unmodified features of the prefix verb are token identical with the corresponding values of the base verb.

Most prefixes appear in distinct but semantically related rules, resulting in polysemous prefixes. For example. combined with some stative verbs, 'durch' signifies "VERB during a certain period of time", as in

\section{(4) durch + leben ('through' + 'live') $\Rightarrow$ durchleben ("live through")}

Specifying the set of adequate bases implicitly by selection restrictions allows to elegantly capture generalizations. For example, we can specify at the feature structure for verbs of motion that they can only combine with the instance of 'durch' denoting "VERB through a space".

The productivity of a word formation rule is a complex notion (Kastovsky, 1986; Bauer, 1988; Mayo et al., 1995). For our purposes, a rule is productive if it applies to all bases which satisfy a common description such as "state" or "transitive verb". A rule only provides patterns for analogical forma-

\footnotetext{
${ }^{1}$ Here, aspect denotes certain general verb classes (Binnick. 1092; Comrie. 1992) such as state, activity, accomplishment, and achievement (Vendler, 195i).
} 
tions; the frequency of application and acceptability of results also indicate its degree of productivity.

\section{Prefix Semantics in HPSG}

The main advantage of HPSG (Head Driven Phrase Structure Grammar, (Pollard and Sag, 1994), for German see e.g.(Kathol, 1995)) is that it is both a formalism with strong ties to logic and knowledge representation and a linguistic theory. Much research in HPSG focuses on the structure of the lexicon. e.g. (Davis, 1997). However, work on semantics and morphology in HPSG is relatively scarce.

\subsection{Previous Work}

Most HPSG work on German affixation focuses on the suffix -bar, which can combine with verbs, most of them transitive, to form an adjective.

(Frieger and Nerbonne, 1992) (KN) assign separate lexical entries to affixes and express selection restrictions by typing and subcategorization frames. In their model, -bar is of sort bar-suff and subcategorizes for verbs of sort bar-verb to form adjectives of sort bar-comp-adj. Complex words have a headed binary structure, with the affix as head. In keeping with the HPSG Semantics Principle, the semantics of the complex word is structure shared with the semantics of the head.

(Riehemann, 1993) found that subcategorization frames were incompatible with her data. Instead of a word syntactic approach with separate lexical entries for affixes, she describes the formation of baradjectives via a lexical inheritance hierarchy of sorts. Different sorts correspond to different types of verbal bases (transitive, dative, etc.). New adjectives are formed in analogy to existing ones.

Although Riehemann's approach is very elegant, it is not adequate for verb prefixes. Most prefixes can be separated from the verb depending on their phonological level. ${ }^{2}$ Example:

Ich mache die Tür zu. ('I close the door'; zumachen = 'to close')

Therefore, a word syntactic approach and separate lexical entries for verb prefixes may well be adequate.

(Witte, 1997) also advocates a word syntactic approach. His semantic representation relies on (Davis. 1997). (Light, 1996) bases his semantic representations on first order logic, but he does not use HPSG.

\subsection{Verb Prefixes}

Fig. 1 presents the prefix-related part of the sort hierarchy. The sort verb-prefix specifies typical fea-

\footnotetext{
${ }^{2}$ Lexical Phonology (Mohanan, 1987) assumes several levels of rules.
}

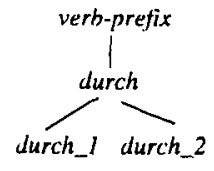

Figure 1: Part of the sort hierarchy for verb prefixes

tures of verb prefixes. Each prefix $p$ is assigned a sort $p$ with subsorts $p_{1} \ldots, p_{n}$ for each potential meaning. Relevant verb classes, such as semantic fields or Vendler classes, are also specified using sorts.

Following KN. I assume that the prefix is the head of complex affix words, but like Riehemann, I do not assume a binary structure. The internal structure of a complex derived word is given in Fig. 2. Morphological information is given at the feature MOR.PII. MORPH|LEVEL specifies separability (1 - unseparable, 2 - separable). MoRPH|DTRs the internal structure, and MORPH|B.ASE the base form.

Each verb has a complex feature Prefix located at SYNSEM|LOC|CAT. For each prefix $p$, the value of the subfeature PREFIX $\mid p$ points to the adeculute prefix meaning. For example, if the instance of 'durch' corresponding to (2) is labelled durch_1, we get PREFIX|DCRCH: 1 in the lexical entry for 'eilen'. A verb can only combine with prefixes for which an instance is specified at PRErIx. Regarding semantics. we focus on aspectual classes. The semantic framework chosen here is Lexical Conceptual Structure, which has been applied successfully to the interface between morphology and lexical semantics by e.g. (Rappaport Hovav and Levin, in press). The representation of Vendler classes is adapted from (Van Valin. 1990). Class is specified at SYNSEM|LOC|CONTENT|CLASS.

Prefix entries are heavily underspecified. For example, the entry for 'durch' can be derived from Fig. 2 by deleting all information specific to the COMPlement eilen'. except for the value of PRFFIX|DIRCII. The semantics of the complex word is composed at the head and then structure shared with the whole word, in accordance with the Semantics Principle. A prefix can only be combined with verbs with an adequate feature value at PRFrIX.

\section{Conclusion and Further Work}

The representation of the relevant semantics will formalized more rigorously. Hypotheses will be checked with the data, using a more refined, statistically motivated notion of productivity. The theory will also be implemented in an adequate lexical knowledge 


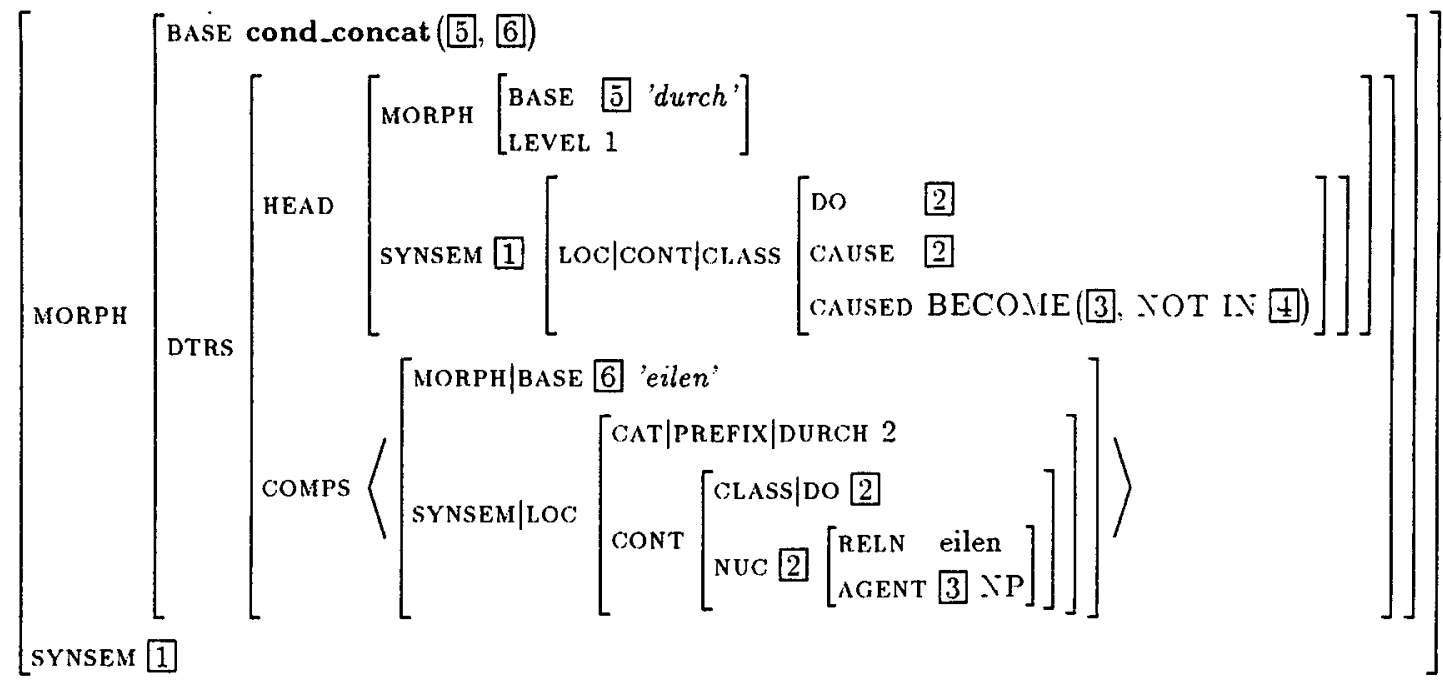

Figure 2: Partial lexical entry for 'durcheilen'. 4 refers to the direct object. 3 to the subject

representation language.

\section{Acknowledgements}

Thanks to Bernhard Schröder and three anonymous reviewers for their valuable comments. This research was partially supported by the Studienstiftung des deutschen Volkes and ERASMUS.

\section{References}

L. Bauer. 1988. Introducing Linguistic Morphology. Edinburgh University Press, Edinburgh.

L. Bauer. 1990. Be-heading the word. J. Linguistics, 26:1-31.

R. Binnick. 1992. Time and the Verb. Oxford University Press, Oxford.

B. Comrie. 1992. Aspect. Cambridge University Press, Cambridge.

A. Davis. 1997. Lexical Semantics and Linking and the Hierarchical Lexicon. Ph.D. thesis, Department of Linguistics, Stanford University.

D. Kastovsky. 1986. The problem of productivity in word-formation. Linguistics, 24:585-600.

A. Kathol. 1995. Linearization-Based German Syntax. Ph.D. thesis, Department of Linguistics, Stanford University.

H.-U. Krieger and J. Nerbonne. 1992. Feature-based inheritance networks for computational lexicons.
In Ted Briscoe, Valeria de Paiva, and Ann Copestake, editors, Inheritance, Defaults and the Lexicon, chapter $T$, pages 90-136. Cambridge University Press.

M. Light. 1996. Morphological Cues for Lexical Semantics. Ph.D. thesis. Department of Computer Science, University of Rochester.

B. Mayo, M.-T. Schepping. C. Schwarze, and A. Zalfanella. 1995. Semantics in the derivational morphology of Italian: implications for the structure of the lexicon. Linguistics. 33:583-638.

K.P. Mohanan. 1987. The Theory of Lexical Phonology. Reidel, Dordrecht.

C. Pollard and I. Sag. 1994. Head-Driven Phrase Structure Grammar. University of Chicago Press.

M. Rappaport Hovar and B. Levin. in press. Morphology and lexical semantics. In A. Zwicky and A. Spencer. editors. Handbook of Morphology. Blackwell, Oxford.

S. Riehemann. 1993. Word formation in lexical type hierarchies - a case study of bar-adjectives in German. Master's thesis, Lniversität Tübingen. SfSReport--02-93.

R.D. Van Valin. 1990. Semantic parameters of split intransitivity. Language, 66:221-260.

Z. Vendler. 1957. Verbs and times. Philosophical Review, 56:143-160.

J. Witte. 1997. Compositional semantics for resultative separable prefix constructions in German. In Proc. HPSG 4. 